\title{
Desmoplastic trichoepithelioma and melanocytic nevus: Dermoscopic and reflectance confocal microscopy presentation of a rare collision tumor
}

André Oliveira, MD, ${ }^{\mathrm{a}}$ Edith Arzberger, $\mathrm{MD},{ }^{\mathrm{b}}$ Iris Zalaudek, MD, ${ }^{\mathrm{b}}$ and Rainer Hofmann-Wellenhof, MD ${ }^{\mathrm{b}}$ Lisbon, Portugal, and Graz, Austria

\section{CLINICAL PRESENTATION}

A 27-year-old woman presented with a 2-year history of an asymptomatic papule located on her right cheek. The physical examination revealed a firm, well-defined with a raised annular border, skincolored papule, $5 \mathrm{~mm}$ in maximum diameter.

\section{DERMOSCOPIC APPEARANCE}

Sharply focused, fine arborizing vessels, mostly at the periphery, were observed on a white-ivory background in the upper half of the lesion and structureless light-brown vessels were observed in the lower half. Few white clods, probably corresponding to horn cysts, were also seen (Fig 1).

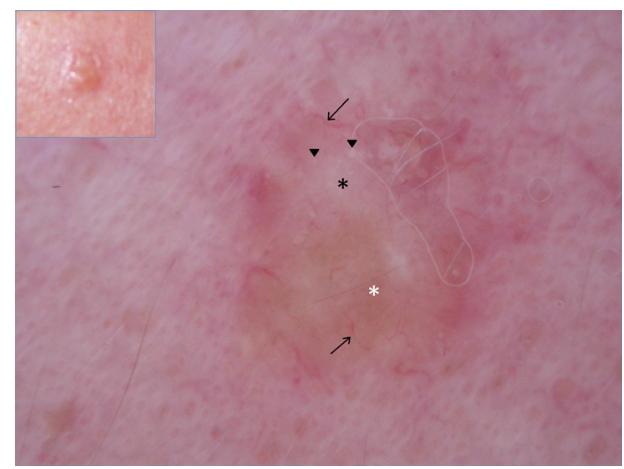

Fig 1. Desmoplastic trichoepithelioma and melanocytic nevus (collision tumor). Dermoscopy of the skin-colored papule on the right cheek (clinical detail) disclosed sharply focused, fine arborizing vessels (arrows), mostly at the periphery on a white-ivory background (black asterisk) in the upper half of the lesion and structureless light-brown (white asterisk) in the lower half. Few white clods (arrowheads) probably corresponding to horn cysts were also seen. There were no leaflike structures, ovoid nests, or shiny-white streaks.

\section{CONFOCAL MICROSCOPY APPEARANCE}

Dark, small, round, and elongated tumor islands were seen in the superficial dermis. Within these structures, round, small black spaces were filled with highly refractile material (early horn cysts). Brightly refractile collagen arranged in parallel bundles was seen surrounding the tumor islands and also some dilated vessels throughout the stroma. Compact, larger, ovoid, highly refractile structures were seen within a few tumor islands, representing focus of tumor calcification. At the dermalepidermal junction, a meshwork pattern with edged papillae, junctional thickenings, and nests were observed (Fig 2).

\footnotetext{
From the Department of Dermatology, Hospital de Curry Cabral -

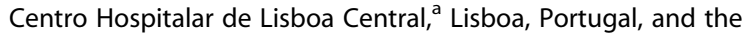
Department of Dermatology, Medical University of Graz, Graz, Austria. ${ }^{\mathrm{b}}$

Publication of this article was supported by $3 \mathrm{Gen}$.

Funding sources: None.

Conflicts of interest: None declared.
}

\footnotetext{
Reprint requests: André Oliveira, MD, Department of Dermatology, Hospital de Curry Cabral - Centro Hospitalar de Lisboa Central, 1169-045 Lisboa, Portugal. E-mail: andre.oliveira@sapo.pt. J Am Acad Dermatol 2015;72:S13-5. 0190-9622/\$36.00

(c) 2014 by the American Academy of Dermatology, Inc. http://dx.doi.org/10.1016/j.jaad.2014.03.047
} 

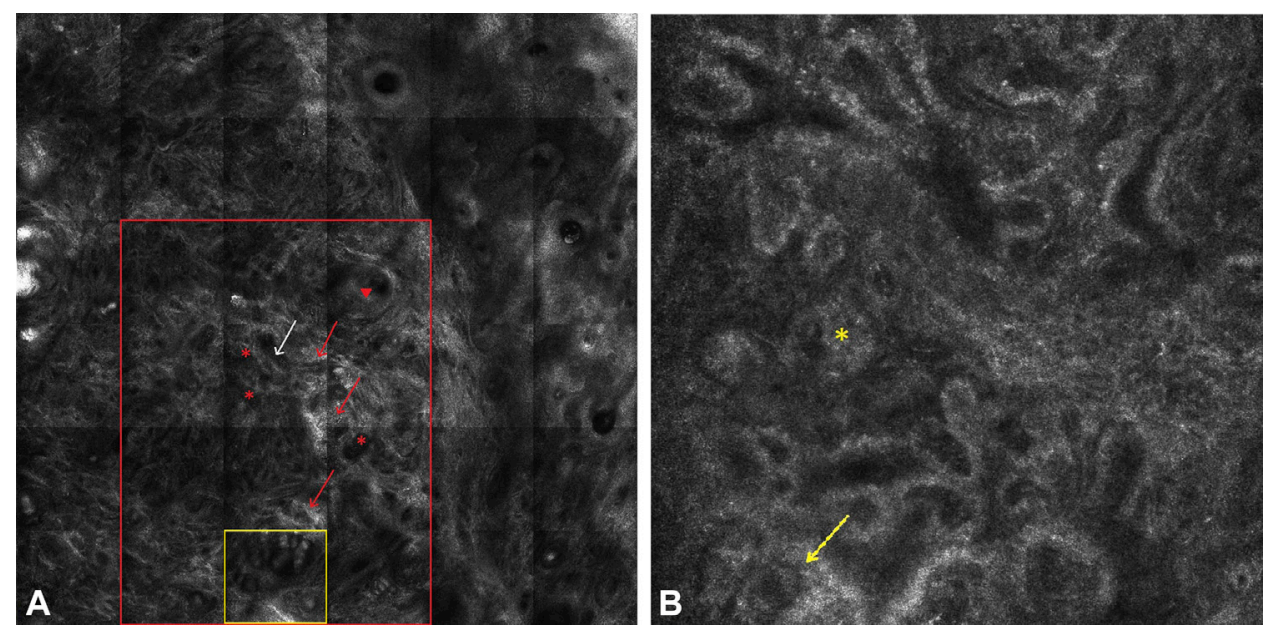

Fig 2. Desmoplastic trichoepithelioma and melanocytic nevus (collision tumor). Reflectance confocal microscopy (RCM) examination (A, RCM mosaic, $3 \times 3 \mathrm{~mm}$; $\mathbf{B}$, basic image, $0.5 \times$ $0.5 \mathrm{~mm}$ ) revealed numerous dark, round, and elongated tumor islands in the superficial dermis. Within these structures, round, small black spaces were filled with highly refractile material corresponding to early horn cysts (red asterisks). Brightly refractile collagen arranged in parallel bundles was seen surrounding the tumor islands (red arrows) and also dilated vessels (white arrow). Larger, ovoid, highly refractile structures were seen within a few dark tumor islands representing focus of tumor calcification (yellow square). At the dermal-epidermal junction, a meshwork pattern with edged papillae, junctional thickenings ( yellow arrow), and nests ( yellow asterisk) were observed.

\section{HISTOLOGIC DIAGNOSIS}

Histopathologic examination confirmed a collision tumor between a desmoplastic trichoepithelioma (DTE) with focus of calcification and a melanocytic nevus (Fig 3).
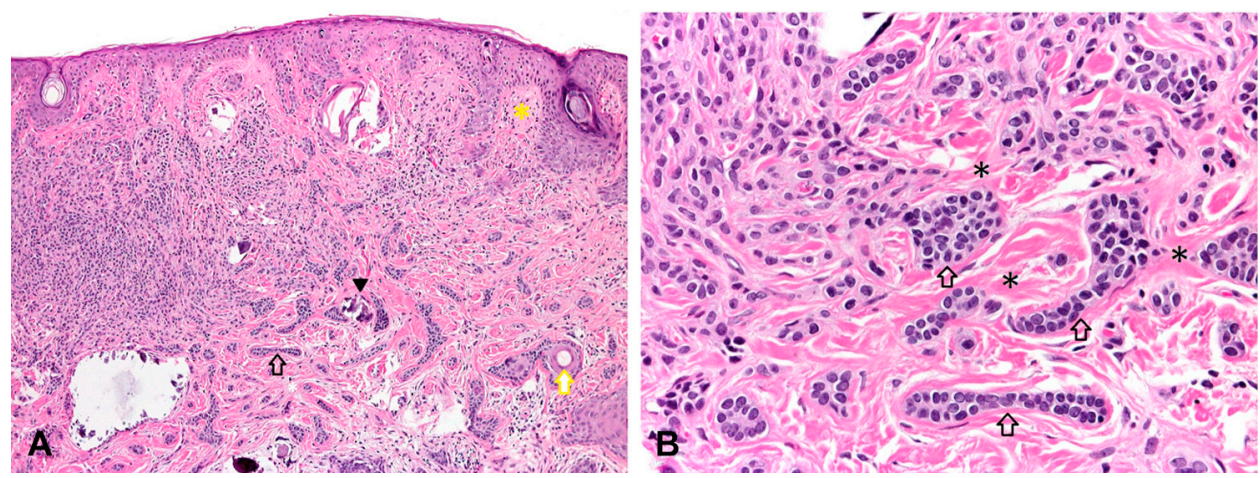

Fig 3. Desmoplastic trichoepithelioma and melanocytic nevus (collision tumor). Histopathologic examination showed a collision tumor between a desmoplastic trichoepithelioma with focus of calcification and a melanocytic nevus ( yellow asterisk). Note narrow strands of tumor cells composed of small basaloid cells without atypia or mitosis (black arrow), horn cysts (yellow arrow), and some areas of calcification (arrowhead) in a densely collagenous stroma (black asterisks). The desmoplastic stroma correlates with the white-ivory background seen in dermoscopy and with the brightly refractile parallel bundles of collagen in reflectance confocal microscopy (RCM). The strands of tumor cells correlate with the dark, small, round structures observed in RCM, while the horn cysts correlate with the white clods featured in dermoscopy and the highly refractile structures observed within the dark tumor islands in RCM. The structureless brown area seen in dermoscopy probably corresponds to the melanocytic nevus. (A, Hematoxylin and eosin stain; original magnification $\times 40$. B. Hematoxylin and eosin stain; original magnification $\times 400$.) 


\section{KEY MESSAGE}

DTE is a benign adnexal tumor. Although rare, typical clinical, dermoscopic, and reflectance confocal microscopy features of DTE were seen here with an associated melanocytic nevus. ${ }^{1}$ To our knowledge, this is the first report of dermoscopic and reflectance confocal microscopy presentation of this rare collision tumor, supporting the role of these noninvasive techniques as an aid to its histopathologic diagnosis. ${ }^{2}$

\section{REFERENCES}

1. Ardigo M, Zieff J, Scope A, Gill M, Spencer P, Deng L, et al. Dermoscopic and reflectance confocal microscopy findings of trichoepithelioma. Dermatology 2007;215:354-8.

2. Moscarella E, Rabinovitz H, Oliviero MC, Brown L, Longo C, Zalaudek I, et al. The role of reflectance confocal microscopy as an aid in the diagnosis of collision tumors. Dermatology 2013;227:109-17. 